\title{
ENVIRONMENTAL EDUCATION FOR SUSTAINABLE DEVELOPMENT: A STUDY CONDUCTED IN THE SCHOOLS OF GREATER GUWAHATI, ASSAM
}

\section{MOYURI SARMA}

Assistant Professor, Department of Education, Gauhati University, Assam, India

Environmental education is a process that creates awareness and understanding of the relationship of human beings with their ultimate environments - natural, man-made, cultural and technological. Environmental Education for Sustainable Development (EESD) is a dynamic concept that utilizes all aspects of public awareness, education and training to create or enhance an understanding of the linkages among the issues of sustainable development and to develop the knowledge, skills, perspectives, and values which will empower people of all ages to assume responsibility for creating and enjoying a sustainable future (UNESCO, 2004). Environment and Sustainable Development implies a shift from viewing education as a delivery mechanism, to the realization that we all are learners and the effort for sustainable development must begin in villages and cities, schools and universities, corporate offices and in all the offices of the state and central government. Therefore, in the present study an attempt has been made (i) To assess the student's knowledge, behavioral attitudes, and actions towards environmental problems, issues, conservation and protection of biodiversity (ii) To investigate the environmental education awareness of school teachers in relation to the type of management, residential background, and gender. It has been found out that there was a statistically significant difference between the pre and post test assessments on student's environmental knowledge, behavior, attitude, and skills. Students, who have been exposed to active EESD teaching strategies, have gained more knowledge, behavior, attitude and skills on environment. While majority of the teachers involved in Environmental Education employed conventional text book methods, a few of them occasionally used other methods, such as informal discussion and group projects as well as resources, such as newspaper cuttings, Environmental Education learning packages, and environment-related web pages. In addition, some teachers promoted Environmental Education through extra-curricular activities.
\end{abstract}

KEYWORDS: Environmental Education, Sustainable Development \& School Education

Received: Jun 10, 2017; Accepted: Jun 25, 2017; Published: Jul 06, 2017; Paper Id.: IJCSEIERDAUG20172

We abuse land because we regard it as a commodity

Belonging to us. When we see land as a community to which

We belong; we may begin to use it with love and respect

-Aldo Leopold, Sand County Almanac

\section{INTRODUCTION}

Environmental education is gaining prominence in the light of the environmental challenges that are facing the society, most importantly the developing nations. Issues concerning environmental degradation, climatic change, natural calamities, indiscriminate dumping of waste, unhygienic living and unkempt environment may find solution through imparting environmental education at all levels of education most importantly at the secondary level. 
According to United States Environmental Education Act, 1970

"Environmental Education is the educational process dealing with man's relationship with his natural and manmade surroundings and includes the relation of population, pollution, resource allocation and depletion, conservation, transportation, technology and urban and rural planning to the total human environment" ${ }_{1}$

Environmental education has gained worldwide momentum at secondary level of education during the last few decades. References of inclusion of environmental education in the Indian school curricula have been found in the recommendations of Kothari Commission (1964-66) long back. The Commission mentioned that, "Environmental activities will lead to study of natural sciences, physical sciences, geography and history and civic, construction and creative skills provide the basis for the practice of healthy living will serve as the foundation for environmental education.”, 2 The National Curriculum Framework for school Education(NCFSE) of 1998,2000 and 2005 have highlighted the need of inclusion of Environmental Education at secondary level and accordingly environmental education is imparted through text books and by some other eco-friendly activities in the schools. In pursuance of the responsibility entrusted by the honorable Supreme Court of India to NCERT to prepare syllabus of environmental education for the different stages of education, syllabi were published for the secondary focusing the environmental issue to the students' exposure. Likewise in the states' secondary schools too text books and environmental courses are being prepared by the SCERTs. Moreover, in order to encourage and mobilize participation of school children in various environmental conservation activities in the localities a school programme known as National Green Crops was initiated by the Government of India and under this programme eco-clubs were formed by the student members from classes VI to X. Such eco-clubs of the schools undertake various programmes on environmental issues concerning protection and improvement of environment.

Sustainable development, as a concept, emerged in 1970s along with the development of industrialization. Especially in 1987, with the report entitled -Our Common Futurell (Brundtland Report, 2002) published by World Commission on Environment and Development, sustainable development concept which has the principle of development without disregarding environment has received a great deal of attention throughout the world. (Ercoskun, 2005). The concept of sustainable development is an important milestone in environmental theory because it points out how society itself should be organized, and not simply why certain environmental protections should be adopted or how they can be best implemented. This ambitious interpretation is widely shared by business leaders, policy activists, and academics alike. Of course, just how much social and economic change is necessary to achieve sustainability depends upon how - unsustainable\|l one believes the present to be. Many advocates of the idea clearly believe the present to be quite unsustainable and thus are prepared for radical change (Taylor, 2002).

Sustainable Development/Environmental education for sustainable development (EESD) is a concept encompassing a vision of education that seeks to empower people of all ages to assume responsibility for creating a sustainable future. For many years, environmental education has sought to develop knowledge about the environment and to establish an ethic of caring towards the natural world. It has also grown over time to recognize the need to engage with many different interests in society in order to address environmental issues. Environmental education for sustainability acknowledges what has always been true, that how people perceive and interact with their environment (their worldviews) cannot be separated from the society and the culture they live in. 


\section{Instructional Strategies Used in Active Environmental Education}

A variety of instructional strategies and experiential approaches were used in active environmental education for facilitating sustainable development. These include classroom sessions, practical, nature study, active-learning and creative drama and small projects.

Actual strategies employed were (as suggested by Stone, 2007):

- $\quad$ Outdoor adventures and experiences

- Educational camping

- $\quad$ Field trips

- $\quad$ Fieldwork

- Wilderness trails and nature walks

- Experiments

Inquiry-based learning, activities and laboratories provide students with opportunities to collect, analyze, interpret and present data. In addition, a variety of instructional strategies were also adapted that included- documentary film shows, case studies, classroom debates, group presentations, simulation games, drama and small projects as suggested by Heyman (1982), Gifford (2002) Proulx, (2004). Students may be asked to formulate their vision for the future of the city and air and water quality status besides biodiversity as well as solid waste issues. Students may also be encouraged to take photographs of nature and wildlife instead of collection of samples/live specimens so that they can inculcate a culture of conservation into their day today interactions with nature and wildlife.

Keeping in view the above discussion, the present paper is an attempt to study the importance of environmental education in view of the introduction of Environmental Education in the school level, which may contribute in teaching children about conservation of resources as well as ensuring environmental security. Hence, the investigator tried to study student's knowledge, behavioral attitudes, and actions towards environmental problems, issues, conservation and protection of biodiversity and teachers perception of environmental education programme.

\section{OBJECTIVES OF THE STUDY}

- To assess the student's knowledge, behavioral attitudes, and actions towards environmental problems, issues, conservation and protection of biodiversity

- To enquire teachers' perception of environmental education programme imparted in schools.

\section{Hypothesis}

$\mathrm{H}_{01}$ : There exists no significant difference in the students being exposed to EESD and not being exposed to EESD in relation to knowledge, behavioral attitudes, and actions towards environmental problems, issues, conservation and protection of biodiversity. 


\section{METHODOLOGY}

The present study is descriptive in nature and the sample was selected using purposive and stratified random sampling technique. Here, four schools have been selected \{2Govt (rural) and 2 privately (urban) managed . The study sample consisted of 240 students. The age group of the select students was ranged between 13 and15 years. 52\% were exposed to EESD programme and $48 \%$ represents not being exposed to EESD programme. The sample for teachers was 28 (male 18 female 10).

Tools

For the present study, Questions were prepared with slight modifications of items from existing questionnaires (Kostova, 2008 and Hagenbuch et. al., 2009). The questions are grouped into four categories to compare overall reported changes in knowledge, attitudes, behavior and skills on air, water, biodiversity conservation and solid waste management. Questions used a standard five-point Likert scale ranging from 1(strongly agree) to 5 (strongly disagree).

\section{Statistical Operations}

The data collected were analyzed with large sample test and through simple percentage The hypothesis was tested at 0.05 level of significance

\section{RESULTS}

$\mathrm{H}_{01}$ : There is no significant difference in the students being exposed to EESD and not being exposed to EESD in relation to knowledge, behavioural attitudes, and actions towards environmental problems, issues, conservation and protection of biodiversity.

Table 1: Large Sample Test Analysis on Difference in Students' Knowledge, Behavioral Attitudes, and Actions towards Environmental Problems, Issues, Conservation and Protection of Biodiversity

\begin{tabular}{|l|c|c|}
\hline \multicolumn{1}{|c|}{ Particulars } & Mean & Sig. \\
\hline Students being exposed to EESD Programme & 3.6194 & \multirow{2}{*}{.031} \\
\cline { 1 - 2 } Students not being exposed to EESD Programme & 3.1000 & \\
\hline
\end{tabular}

As the value sig. is less than $.05(\mathrm{sig}=.031)$ so, the hypothesis is rejected. There exists significant difference between students who have been exposed to active EESD teaching strategies and those not being exposed to such innovative strategies. The students who have been exposed to active EESD strategies have gained more knowledge, behavior, attitude and skills on environment in comparison to the other group.

(ii) To enquire teachers' perception of environmental education programme imparted in schools.

Table 2: Responses of Teachers

\begin{tabular}{|c|c|c|c|c|}
\hline Particulars & Yes & No & Not Sure & Total \\
\hline Adequate knowledge and training on Environmental Education & $16(57 \%)$ & $5(17 \%)$ & $7(26 \%)$ & $28(100 \%)$ \\
\hline $\begin{array}{l}\text { Variety of teaching methods (informal discussion and group } \\
\text { projects as well as resources, such as newspaper cuttings, } \\
\text { Environmental Education learning packages, and environment- } \\
\text { related web pages) }\end{array}$ & $13(46 \%)$ & $15(54 \%)$ & - & $28(100 \%)$ \\
\hline Regular practices of extracurricular activities & $23(82 \%)$ & $1(4 \%)$ & $4(14 \%)$ & $28(100 \%)$ \\
\hline Activities of Eco Club & $24(87 \%)$ & $3(11 \%)$ & $1(2 \%)$ & $28(100 \%)$ \\
\hline Observance of World Environment Day, Earth Day, etc. & $21(78 \%)$ & $6(22 \%)$ & $3(10 \%)$ & $28(100 \%)$ \\
\hline Field Study & $24(87 \%)$ & $4(13 \%)$ & - & $28(100 \%)$ \\
\hline
\end{tabular}




\begin{tabular}{|l|l|l|l|l|}
\hline Tree Plantation & $17(61 \%)$ & $4(14 \%)$ & $7(25 \%)$ & \\
\hline Cleanliness drives in school \& locality & $15(53 \%)$ & $6(22 \%)$ & $7(25 \%)$ & $28(100 \%)$ \\
\hline Adequate class time & $15(54 \%)$ & $9(33 \%)$ & $4(13 \%)$ & $28(100 \%)$ \\
\hline
\end{tabular}

Teachers were keener to teach Environmental Education if they held more favourable attitudes towards Environmental Education, had more skills in teaching Environmental Education, realized the relevance of Environmental Education, and would actually want to take more Environmental Education classes if there were fewer constraints. On the basis of the responses of the teachers irrespective of their management type, location and gender it may be stated that the teachers have a positive attitude towards Environmental Education programme. But only 57\% teachers said they have adequate knowledge of Environmental Education and the rest had given a negative reply. Again $46 \%$ teachers out of the total teacher respondents replied that they use variety of teaching methods (viz innovative methods, news paper cutting, group project, teaching through web pages) to teach the subject. The rest of the teachers use traditional text book method for teaching. However, $82 \%$ teachers' reply is very encouraging in regards to regular practices of extracurricular activities for giving awareness, knowledge and training on environmental issues. $87 \%$ of the teachers replied that there are eco-clubs in the schools which are taking initiative in the environmental awareness programmes. Again it has been found that the teacher's initiatives and participation in the observance of important days like World Environment Day, Earth Day in schools may encourage teachers in teaching environmental education for sustainable development. Further, as many as $87 \%$ of the teacher respondents said that they conducted field survey for imparting knowledge and experience on issues of environmental degradation like soil and water pollution and sustainable development through various eco friendly methods. But the teachers also mentioned the problem related to limitation of class timing and huge syllabus which hinder in the study of their subject. 33\% teachers said that they find problem due to inadequate time of class though 54\% teachers replied positively. However, the findings from this study are subject to a limitation. There was no observation with direct participation of the researcher or class room observation to substantiate the self reported actual practices of the case study of teacher's perception on EE. Despite this limitation, the study provided an initial understanding of teachers' perceptions on environmental education in Greater Guwahati area, implications for curriculum and pedagogical strategies for environmental science education in the future.

\section{CONCLUSIONS}

Environmental degradation is a pertinent issue of worldwide concern. People across countries and all forms of bio diversity are worst affected by environmental challenges. Environmental awareness may help in conservation consciousness as well as leading a sustainable life. It is an established fact that conservation and restoration of environment depends not only on the study of environmental education at various levels but its success depends on the strategies and techniques adopted by the practitioners in spreading the message among the stakeholders. From the study it may be concluded that the appropriate strategies should be adopted for teaching environmental education in order to achieve the broad objectives of studying the subject. Therefore, it is suggested to intensify the programme of environmental education in all levels more particularly at the secondary level by reflecting on the pertinent issues concerning environment. Students irrespective of Vlocality, gender and family background must imbibe and acquire environmental knowledge and awareness for restoring the Mother Nature.

\section{REFERENCES}

1. Bhagabati, A.(2011): “Environmental Education” in Das, S. (ed) Environmental Education Concepts, Issues \& Problems. 
Ghy: K.K.Publication. pp.13.

2. Choudhury, K. “Environmental Education” in Das, S. (ed) Environmental Education Concepts, Issues \& Problems. Ghy: K.K.Publication. pp.246.

3. Gogoi, J. P. (2012): “The Policies of Development and its Impact on Environment: The Human Security Dimensions in Northeast India" in Das, J.K. (ed) Agenda for Assam and the North East Ghy: EBH Publication. pp.7

4. Akomolafe C.O. (2011) Impact of Personal Factors on Environmental Education in Tertiary Institutions in Ekiti State , Nigeria. International Journal for Cross-Disciplinary Subjects in Education (IJCDSE), Special Issue Volume 1 Issue 1, (2011)

5. Aomolafe, C.O., (2011), Environmental Awareness Knowledge and students' environmental attitude in tertiary institutions in Ekiti State. Canada International Conference in Education (CICE-2011)

6. Arcurary T.A.,(1990), Environmental Attitude and Environmental Knowledge Human organization. Volume 49 No 4: pp 300 